\title{
TEATRO DE INVASÃO: O TEATRO DE RUA SOBRE UM CHÃO QUE SE PODE SOLTAR
}

\author{
Daniele Santos1- \\ Mestranda em Artes Cênicas \\ Universidade Federal do Estado Do Rio de Janeiro- UNIRIO. \\ umadiretriz@gmail.com
}

Para compreendermos em que contexto se dá a manifestação contemporânea denominada Teatro de Invasão, assim como alguns dos conceitos nela imbricados, propõe-se resgatar alguns traços do Teatro Moderno que reverberam diretamente na multiplicidade de poéticas cênicas que compõem o Teatro Contemporâneo.

As pesquisas sobre o Teatro Moderno reiteram que a revolução tecnológica ocorrida nos últimos anos do século XIX contribuiu diretamente para o que foi chamado de "surgimento do encenador", na medida em que pode proporcionar um inicial apagamento de fronteiras e distâncias entre países, fazendo com que as pesquisas teóricas e as práticas teatrais subsequentes circulassem com maior facilidade, além de ter proporcionado a descoberta dos recursos da iluminação elétrica.

Neste sentido, houve um avanço significativo no pensamento da cena enquanto "representação feita sob a perspectiva de um sistema de sentido" (PAVIS,2013:03), consequentemente, da iluminação para além da sua funcionalidade técnica, sendo entendida também em seu caráter poético. Assim, a luz "torna-se elemento preponderante da cenografia." (ROUBINE,1998:21).

\footnotetext{
${ }^{1}$ Daniele Santos é mestranda em Artes Cênicas pela Universidade Federal do Estado do Rio de Janeiro- UNIRIO. Possui graduação em Artes Cênicas com Habilitação em Direção Teatral pela Universidade Federal do Rio de Janeiro- UFRJ /2008 e Especialização em Arte, cultura e sociedade no Brasil pela Universidade Veiga de AlmeidaUVA/2013. Trabalhou durante três anos como Professora da sala de leitura e Contadora de histórias no colégio Espaço Educação LTDA e durante dois anos como Tutora a distância do curso de Artes Cênicas e Música da Universidade de Brasília- UNB. Atualmente trabalha como Professora Tutora do Instituto Arte na Escola. Tem experiência na área de Artes e Literatura, com ênfase em Artes.
} 
O século $X X$, portanto, será palco dos mais diversos questionamentos sobre a representação teatral da maneira como vinha sendo concebida até então. Assim, para Jean Jacques Roubine:

\begin{abstract}
O debate que acompanha toda a prática teatral do século XX coloca em oposição, em diversos planos e sob denominações que variam ao sabor das épocas, a tentação entre a representação figurativa do real (naturalismo) e a do irrealismo (simbolismo), não seria tão intenso, nem tão fecundo, sem dúvida, se não fosse sustentado por uma revolução tecnológica baseada na eletricidade. (ROUBINE,1998:23)
\end{abstract}

O embate gerado pelo pensamento sobre a representação acarretará o debate sobre os elementos constituintes da cena como um todo, favorecido pela própria ideia da encenação como geradora de unidade do espetáculo. Assim, o questionamento do teatro concebido enquanto "retomada de uma ideia ou uma realidade anterior [...] que apresenta uma segunda vez e torna presente aquilo que estava ausente"(PAVIS,2013:03), ou seja, o teatro concebido como representação mimética da realidade vai reverberar no pensamento sobre o texto dramático, o trabalho de ator, indumentária, etc. além das revoluções propostas ao espaço cênico nas suas configurações arquitetônicas, cenográficas e na própria interação com o espectador.

Dessa forma, a partir do movimento de revisão da cena teatral de uma maneira geral proposto pelos movimentos de vanguarda do Teatro Moderno, chegaremos ao alargamento de conceitos fundamentais para os questionamentos apresentados pelo Teatro de Invasão; como o conceito de "teatralidade". Longe de ser entendido em consenso pelos pesquisadores do tema, este conceito, no entanto, foi revisado ao longo da história, ganhando novas camadas para se pensar o contemporâneo. Assim, Josette Féral opõe ao conceito de teatralidade, para ela ligado a reunião das operações de criação e recepção, ao conceito de performatividade. No entanto, segundo Silvia Fernandes:

Ainda que oponha os dois conceitos, percebe-se que uma das principais intenções da ensaísta é definir a teatralidade como o resultado de um jogo de forças entre as duas realidades em ação [...] 
a performatividade aproxima-se do conceito de teatro genérico de Jean-François Lyotard, um teatro de intensidades, forças e pulsões de presença, que tenta esquivar-se à lógica da representação. (FERNANDES,2010:123)

Ainda neste sentido, conforme apontado pelos estudos de Silvia Fernandes, Josette Féral propõe o conceito de "Teatro Performativo" em contraposição que HansThies Lehmann denominou Teatro Pós-Dramático, por considerar a nomeação do teórico alemão como "excessivamente genérica e pouco efetiva" (FERNANDES,2010). Segundo Silvia Fernandes, em concordância com a pesquisadora francesa, tal denominação faz-se necessária pois:

O teatro contemporâneo beneficiou-se amplamente de algumas conquistas da arte da performance, já que as práticas performativas redefiniram os parâmetros que permitem pensar a arte e, evidentemente, tiveram influência radical sobre a cena teatral, que adotou alguns de seus princípios. O principal dele está na origem do termo perfomatividade e foi prospectado a partir das pesquisas de Austin e Searle, que difundiram o conceito pela via dos verbos performativos, colocando a ênfase na realização da própria ação performática e não sobre seu valor de representação[...]Sem dúvida, as operações performativas de produção e transformação cênica de situações são as maiores responsáveis pelo desvio paulatino das exigências da representação enquanto processo centrado na ilusão e no traçado ficcional, em proveito da ação cênica real e do acontecimento instantâneo e não repetível[...]Segundo Féral, essa mutação cênica define uma ruptura epistemológica de tal ordem que é necessário adotar a expressão teatro performativo para qualifica-la (FERNANDES, 2010:125)

Outro conceito que sofreu diversas ressignificações foi o conceito de dramaturgia, antes somente associada à composição de ordem textual. A partir do século XX, no entanto, passou por profunda revisão e ampliou-se para abarcar aspectos como a composição atoral ou a produção de sentido realizada pelo espectador, podendo assim, ser levado ao campo da cenografia para se pensar uma dramaturgia do espaço cênico. Neste sentido, André Carreira esclarece: 
A introdução no campo do teatro de noções de dramaturgia como uma escritura que pode estar instalada no corpo do ator, não apenas redefine a noção de ator, mas propõe repensar nossos conceitos com relação ao teatro. Neste sentido, refletir sobre as relações existentes entre as regras de funcionamento do espaço cênico, do espaço cultural e a construção de textos espetaculares nos espaços abertos da cidade é também pensar a ideia de uma dramaturgia do espaço. (CARREIRA,2008:68).

Tais formulações são importantes para que possamos situar o Teatro de Invasão numa zona fronteiriça onde coexistem conceitos alicerçais para o teatro contemporâneo. Para tanto, busca-se, num primeiro momento, o entendimento do que seja o Teatro de Invasão e seus principais conceitos formadores.

\section{O TEATRO DE INVASÃO E A PERSPECTIVA DA CIDADE COMO DRAMATURGIA}

A ideia de que o Teatro de Invasão pensa a cidade enquanto dramaturgia está, também, diretamente ligada a conceitos provenientes das áreas de urbanismo e geografia cultural, dos quais André Carreira se apropria para pensar o urbano como um espaço permeável. Primeiramente deve-se levar em conta o conceito de "ambiente urbano" na sua diferenciação com o que é chamado de "espaço urbano". Segundo Giulio Carlo Argan (apud CARREIRA,2011:01), "o ambiente urbano seria diferente daquilo que chamamos de espaço urbano [...] o espaço urbano é projetável, é produto de projetos, enquanto o ambiente pode ser condicionado mas não estruturado ou projetado."

Ainda para o historiador, o ambiente está diretamente ligado à sociedade de consumo, sendo ele mesmo um fator opressivo. Para ele: 
A cidade pode ser considerada em si mesma um bem de consumo, isto é um sistema global de informações destinado a determinar o máximo de consumo de informação. Este sistema de informações não seria responsável apenas pela difusão de dados e informações, mas também pela indução de conhecimento e modelos culturais normatizando a vida no urbano, construindo (opressivamente) os padrões de comportamentos. (ARGAN apud CARREIRA,2011:01)

Nesta perspectiva, André Carreira pensa a cidade no plural; no sentido de que uma cidade não pode ser abordada em sua totalidade, visto que se trata de um sistema de informações definido pelos repertórios de usos de seus habitantes. Assim, "trata-se de um espaço percebido a partir de seus múltiplos fragmentos e de seus usos diversos e sobrepostos. Usos que estabelecem zonas culturais que conformam as "cidades" dentro da cidade." (CARREIRA, 2009:04)

No livro A invenção do cotidiano de Michel de Certeau encontramos uma aproximação aos repertórios de usos aos quais André Carreira se refere e que o autor denomina "texto urbano":

\begin{abstract}
A partir dos limiares onde cessa a visibilidade, vivem os praticantes ordinários da cidade. Forma elementar dessa experiência, elas são caminhantes, pedestres, 'wandersmanner', cujo corpo obedece aos cheios e vazios de um 'texto' urbano que escrevem sem poder lê-lo. Esses praticantes jogam com espaços que não se veem; tem dele um conhecimento tão cego como no corpo-a-corpo amoroso. Os caminhos que se respondem nesse entrelaçamento, poesias ignoradas de que cada corpo é um elemento assinado por muitos outros, escapam à legibilidade. Tudo se passa como se uma espécie de cegueira caracterizasse as práticas organizadoras da cidade habitada. (CERTEAU,1988:171).
\end{abstract}

Entender a cidade enquanto dramaturgia é um processo que deve levar em conta as próprias regras de espetacularização presentes no cotidiano do ambiente urbano em sua produção de sentido. Assim, a cidade "sempre interfere no espetáculo condicionando seu funcionamento e estabelecendo condições de recepção do mesmo, promovendo a produção do signos da cena." (CARREIRA,2009:04)

Por este motivo, seria inviável pensar a cidade enquanto cenografia apenas, na medida em que o espetáculo redefine a cidade mas também é redefinido por seus usos e "aquilo que poderia ficar atrás da cena como elemento cenográfico sempre Revista "O Teatro Transcende" Departamento de Artes - CCEAL da FURB - ISSN 2236-6644 - Blumenau, Vol. 21, №1, p. 16 - 29, 2016 
ocupará interstícios de dramaturgia porque é um dispositivo vivo por onde circulam pessoas em seu cotidiano". (CARREIRA,2009:04).

Assim, o Teatro de Invasão propõe o pensamento sobre a arte no seu âmbito político mas, desvinculada dos discursos comuns que pretendem circunscrever o Teatro de Rua como uma prática artística que se baseia, principalmente, no contato com um público que não tem acesso ao teatro. Para além disso, o teatro de rua é pensado como "prática construtiva da cidade e pretende-se que ele se relacione com a rua como estrutura cultural." (CARREIRA,2011:13). Desta forma, o alcance do Teatro de Rua se amplia e o movimento de "invasão" articula-se diretamente com formas de rompimento do cotidiano; da ordem estabelecida. Assim:

A intervenção artística, insere na lógica funcional da cidade, deslizamentos momentâneos que podem subverter procedimentos cotidianos. O cidadão comum, o usuário do espaço da cidade estrutura rotinas que são importantes tanto para sua inserção nos usos da cidade, como para construção de identidades. As linguagens artísticas que não estão diretamente ligadas com o universo da publicidade ou dos mass media criam espaços de estranhamento com as rotinas da cidade, ainda que mais não seja, porque não reafirmam a lógica do capital (CARREIRA,2010:01)

O Teatro que invade a cidade é, então, um teatro que cria fissuras nas operações do cotidiano, reorganizando-o brevemente, "embaralhando" suas regras. Assim, podemos observar as práticas invasoras sob o viés do jogo, no sentido de que podem ser compreendidas, também, fora da lógica da funcionalidade. Neste sentido, Jean Duvignaud, diz:

A través de la costra endurecida de la vida acostumbrada, agrega, se ve surgir la corriente de atividades inútiles o lúdicas. Por las hendeduras de una sociedad sobredeterminada y sin duda 'bloqueada' un flujo de experiências y de aspiraciones se abre un difícil caminho que, en los medios más diversos, se apoya en prácticas o actitudes cada vez distintas.(DUVIGNAUD,1982:131)

Deste modo, o Teatro de Rua:

Extrapola os muros das salas teatrais e se coloca numa perspectiva muito diversa da abordagem funcional que caracteriza a norma urbana; visita esse lugar como uma ação inútil que busca conquistar um espaço que não lhe pertence. Invade, ainda quando não se sente um invasor, e está ali ocupando uma zona à qual é um estranho e com a qual tem um diálogo que não é simples [...] é sempre um 
intruso que adentra um espaço que pertence aos cidadãos e seus repertórios de usos, às instituições e seus desejos de ordem e funcionalidade, ao trânsito de veículos e mercadorias, com sua imperativa urgência. Uma forma de arte que faz da insistência sua face mais evidente. (CARREIRA,2011:17)

O Teatro que pensa a cidade como dramaturgia, "fruto de um contexto que colocou em discussão a primazia do texto dramático e ampliou a noção de dramaturgia" (VALDEZ, p.1) é também um teatro que flerta com pensamentos provenientes do campo da Performance Art para repensar noções como o trabalho de ator, relação entre atores e espectadores, etc. habitando fronteiras cada vez mais elásticas entre as práticas da arte contemporânea.

\section{A PRÁTICA DO TEATRO DE INVASÃO}

O espaço público urbano, pensado enquanto dramaturgia a qual está aderido fluxo de usuários e sua percepção é um espaço que questiona o prédio teatral enquanto local próprio para a prática desta arte. Assim, por consequência, temos o questionamento da relação comumente estabelecida entre placo e plateia e a tendência das encenações de rua a se configurarem como Obra aberta, na definição de Umberto Eco:

Neste sentido, portanto, uma obra de arte, forma acabada e fechada, é também aberta, isto é, possível de mil interpretações diferentes, sem que isso redunde em alterações de sua irreproduzível singularidade. Cada fruição é, assim, uma 'interpretação' e uma 'execução', pois em cada fruição a obra revive dentro de uma perspectiva original. (ECO,1991:40)

Nesta definição, Umberto Eco parece abordar um caráter genérico das obras de arte; no entanto, esta abertura sugerida pelo autor pela possiblidade de ressignificação da obra, parece ser ampliada quando se trata de um teatro que conta com o imprevisível como fator estruturante. Desta forma, o Teatro de Invasão propõe uma 
abertura que extrapola sua ressignificação poética e abarca o próprio acontecimento cênico que tem como elemento constituinte, o risco, conforme atesta André Carreira:

O elemento do risco é um componente no exercício de apropriação da cidade, em primeiro lugar porque este é um sitio no qual está presente uma série de riscos para a vida e a integridade física das pessoas. Ainda que os riscos digam respeito mais ao imaginário e respondam a uma tensão que parece típica das nossas cidades, estes compõem uma percepção de uma condição fundamental do urbano. A rua é espaço inóspito que se opõe ao conforto e segurança dos espaços íntimos e é isso que atrai o olhar do artista como ponto de partida do processo criativo (CARREIRA,2010:06)

Considerando a relação que o teatro de rua estabelece com o espaço público e seus espectadores, estudiosos do tema aproximam sua prática com algumas propostas dos movimentos vanguardistas do século $X X$, que consideram o espectador como elemento do espetáculo. Em Adolphe Appia, encontramos:

Mais cedo ou mais tarde chegaremos ao que se denominará "sala catedral do futuro", a qual, dentro de um espaço livre, vasto, transformável, acolherá as mais diversas manifestações de nossa vida social e artística, e será o lugar por excelência onde a arte dramática florescerá, com ou sem espectadores[...]O termo representação tornar-se-á pouco a pouco um anacronismo. A arte dramática de amanhã será um ato social ao qual cada um dará sua contribuição (MARTINS apud APPIA, 2014:164)

Nesta perspectiva, guardadas as devidas proporções, o que o Teatro de Invasão sugere, se aproxima bastante do ato social proposto por Adolphe Appia, na medida em que o espectador sai de sua posição pretensamente passiva e participa diretamente do evento teatral, inclusive estando livre para fazer qualquer tipo de interferência; o que no teatro convencional se torna menos possível devido às "regras de convivência" impostas pelo próprio espaço.

Assim, as fronteiras entre realidade e ficção encontram-se abaladas no espetáculo de rua que tem a cidade como dramaturgia, se inserindo no cotidiano de forma a reorganizá-lo. A própria definição do que é encenação e do que é realidade depende do olhar do espectador e é alterada por seu repertório. 
A anexação da realidade proposta por este tipo de espetáculo, questiona o status da representação e o aproxima dos conceitos da Performance Art esgarçando algumas noções, como a de personagem. No entanto, não se trata de um abandono total da representação em detrimento do puro acontecimento, o que ocorre é que o espetáculo se situa numa zona limiar entre o performático e o teatral, como esclarece André Carreira:

\footnotetext{
Um teatro que não se conforma com sua condição de fala tradicional e avança pelas fronteiras do performático, apesar de que isso não implique em afirmar o desaparecimento da condição da representação em favor do puro acontecimento. Estamos dentro de um território no qual a percepção do ator como sujeito estranho ao cotidiano tem uma grande importância na construção do acontecimento. (CARREIRA,2011:20)
}

Nesta direção, o diretor reivindica pesquisas específicas para o ator de rua e que deem conta de prepara-lo para um tipo de espetáculo que tem em seu cerne, o acaso. Não se trata, porém, da tentativa de fechamento da obra, nem mesmo da sugestão de que o acaso não perpasse qualquer obra teatral mas, do entendimento de que seja necessário pensar um treinamento específico para o ator de um teatro que tem o incerto como condição.

Isto posto, torna-se relevante expor alguns momentos acontecidos no espetáculo Das Saborosas Aventuras de Dom Quixote de La Mancha e seu fiel escudeiro Sancho Pança- um capítulo que poderia ter sido (2006), no sentido de tentar dar maior concretude a algumas questões, até então expostas.

\section{DAS SABOROSAS AVENTURAS DE DOM QUIXOTE DE LA MANCHA E SEU FIEL ESCUDEIRO SANCHO PANÇA- UM CAPÍTULO QUE PODERIA TER SIDO}

O espetáculo do grupo "Teatro que Roda" (Goiás) dirigido por André Carreira, propõe a adaptação do romance Dom Quixote de La Mancha e transforma o cavaleiro 
andante de Miguel de Cervantes em um executivo que, cansado de sua rotina, resolve mergulhar em um mundo imaginário de emoções e aventuras. $\mathrm{O}$ executivo passa a acreditar que é Dom Quixote e sai pela cidade em busca de sua amada platônica Dulcinéia (que se apresenta como uma alucinação, vestida de noiva, no decorrer da história). Ele desce de um prédio, numa corda, gritando por sua amada e se destituindo de seu figurino de gravata para incorporar o cavaleiro andante, juntando peças e lixo que encontra pelo caminho. Seu fiel escudeiro Sancho Pança é um catador de lixo vivido pela atriz Liz Eliodoraz.

A proposta do diretor é uma "nova forma de conceber e estruturar aquilo que genericamente chamamos de teatro de rua" (carreira,2011) a começar pelo fato de que o Teatro de Invasão dispensa a necessidade de licenças oficiais para instaurar seus atos artísticos e sua prática. Na adaptação do clássico de Cervantes, a encenação dialoga diretamente com a linguagem do circo e da performance; há, por exemplo, um coro de noivas, comandado pela atriz leda Marçal, este coro interfere na cena quando solicitado por Quixote mas tem, na maior parte do tempo, liberdade para andar pela cidade, performando. A atriz e pesquisadora Denise Pedron conta:

Senti que do contato do coro de noivas com a personagem de Quixote é que nasciam mais movimentos no espaço (...) vivenciei o trabalho do coro de noivas mais como produção de alteração propositiva no cotidiano da cidade, como corporificação subjetiva de afectos e perceptos (DELEUZE,96) do que como composição de cena ou representação de personagem. (PEDRON,2010:02) 


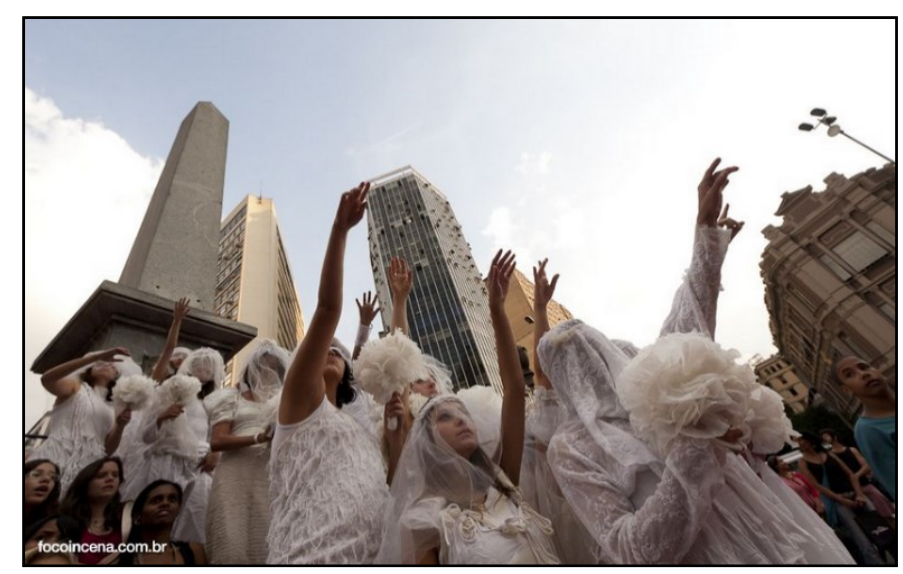

Disponível em: http://www.focoincena.com.br/das-saborosas-aventuras-de-dom-quixote/1633

A partir da fala da atriz podemos observar algumas relações citadas acima no que tange aos momentos proporcionados pela prática da invasão e que dizem respeito à subversão da lógica dos procedimentos cotidianos da cidade. Deve-se perceber a potência imagética da distribuição, pela cidade, do arquétipo da noiva e a multiplicidade de suas significações.

No espetáculo, também podemos observar, a mescla entre público e cena, de modo que há um limite muito tênue de definição do papel do espectador entre apreciador ou personagem da ação, acompanhando-a pela cidade. Assim, podemos ver as figuras de Dom Quixote e Sancho pança, por vezes em destaque, por vezes engolidos pela multidão. Neste sentido, fica clara uma das medidas em que o espetáculo redefine a cidade e é redefinido por ela, anexando a realidade circundante, notando-se que até a mínima movimentação do ator no espaço é mediada pela presença do público e vice-versa e a participação direta deste é não só bem-vinda como inevitável.

Deve-se ainda neste sentido, considerar o elemento do risco, citado anteriormente e que diz respeito ao ato em si, no momento em que é praticado e que não pode ser calculado, na medida em que o Teatro de Invasão se institui no espaço e se apropria dele no momento em que a peça se inicia, sem ensaios prévios no espaço escolhido. Considera-se então muito fortemente o elemento do jogo, que se modifica 
no contato com o público e na percepção sempre renovada de cada espaço onde o espetáculo se apresenta. Assim, a própria forma como o espetáculo se inicia (com Dom quixote descendo de rapel de um prédio para cair nos braços do público) já autoriza as relações de jogo que se estabelecem ao longo do espetáculo.

Estas considerações dizem respeito ao acontecimento do teatro de invasão em sua relação com a rua, a quebra dos fluxos do cotidiano, a relação do jogo que se estabelece como citado acima e o rompimento momentâneo da lógica do capital, movimentadora e delineadora do cotidiano, através do irromper da arte, no lugar do inesperado. A própria disponibilidade que o público demonstra ao acompanhar os atores no percurso do espetáculo já é um exemplo de como o teatro de invasão opera na cidade.

Cabe destacar um dos momentos do espetáculo relativo ao capítulo VIII da primeira parte do livro de Cervantes onde Dom Quixote briga com moinhos de vento. No espetáculo de André Carreira, os moinhos são um trator com várias noivas na caçamba, mais uma vez replicando o arquétipo das noivas pela cidade e pela imaginação de Dom Quixote. Junta-se a isto uma das imagens mais fortes do espetáculo, que diz respeito a sua cena final, onde o coro de noivas joga rosas vermelhas da sacada de um prédio. Esses dois momentos surgem com uma força poética de grande intensidade e dialogam diretamente com os conceitos até então abordados, relativos às relações com o espaço da cidade e sua reestruturação momentânea.

Assim, para concluirmos, podemos dizer que o Teatro de Invasão estabelece um espaço no urbano que corresponde ao espaço potencial onde se dá a experiência do espetáculo de rua. Nele, atores e espectadores são "sujeitos dispostos a correr riscos, a andar nesse chão do mundo que a qualquer momento pode se soltar." (PEDRON,2010:04) 


\section{REFERÊNCIAS}

CARREIRA, André, Ambiente, fluxos e dramaturgias da cidade: materiais do Teatro de Invasão, O percevejo online, no 1, v.1, jun, 2009, p. 1-10.

Procedimentos de um Teatro de Invasão, Cavalo Louco, $\mathrm{n}^{\circ} 5$, dez,2008.p.14-19.

- Teatro de Invasão: Redefinindo a ordem da cidade, In: LIMA, E.F.W.(Org). Espaço e teatro: do edifício teatral à cidade como palco, Rio de Janeiro, 7 letras /FAPERJ,2008, p.68.

Espaço urbano, medo e labirintos dos mitos urbanos. Nov, 2011.

Disponível em : http://pesquisateatral.blogspot.com.br/2011/11/andre-carreiraespaco-urbano-medo-e-os.html. Acesso em Jun, 2015.

Sobre um ator para um teatro que invade a cidade, Moringa Artes do Espetáculo, n² 2, v.2, jul-dez, 2011.

A cidade como dramaturgia do Teatro de Invasão, 2010, Disponível em: $\quad$ http://pt.scribd.com/doc/40287815/Andre-Carreira-A-Cidade-ComoDramaturgia\#scribd. Acesso em: Jul, 2015.p.01/06.

CERTEAU, Michel de, A invenção do cotidiano (Ephraim Ferreira Alves), Petrópolis, RJ, Vozes, 1988, p.171.

DUVIGNAUD, Jean, El Juego del Juego, México, Fondo de Cultura Económica, 1982, p.131.

ECO, Humberto, Obra Aberta, São Paulo, Editora Perspectiva, 1991, p.40. 
FERNANDES, Silvia, Teatralidades Contemporâneas, São Paulo, Editora Perspectiva, 2010, p.123-125.

MARTINS, Lucia Helena. A liv art e o espectador em Das Saborosas Aventuras de Dom Quixote de la Mancha e seu fiel escudeiro Sancho Pança- um capítulo que poderia ter sido. Urdimento- Revista de estudos em Artes Cênicas, n²22, v.1, 2014, p.164.

PAVIS, Patrice, A encenação contemporânea (Nanci Fernandes), São Paulo, Editora Perspectiva, 2013,p.03.

PEDRÓN, Denise. Teatro de Ocupação, Teatro de Intervenção. 2010. Disponível: http://portalabrace.org/1/index.php/verperfil/userprofile/denise\%20araujo. Acesso em: Jun, 2015, p.2-4.

ROUBINE, Jean Jacques. A linguagem da Encenação Teatral (Yan Michalski), Rio de Janeiro, Jorge Zahar Editora, 1998, p.21-23.

VALDEZ, Carmen. 0 espectador das encenações em espaços públicos não convencionais. Disponível em: http://www4.unirio.br/espacoteatral/iv-seminariotexto-carmen.html. Acesso em: Jul, 2015, p.01. 